Tropical Journal of Pharmaceutical Research May 2021; 20 (5): 1079-1083

ISSN: $1596-5996$ (print); 1596-9827 (electronic)

(C) Pharmacotherapy Group, Faculty of Pharmacy, University of Benin, Benin City, 300001 Nigeria.

\title{
Effect of fallopian tube dredging with a combination of hysteroscopy and Traditional Chinese medicine containing marine-derived principles in patients with inflammatory obstruction of fallopian tube
}

\author{
Meng-meng Li ${ }^{1}$, Wei-juan Wang ${ }^{2}$, Feng Huang ${ }^{3}$, Xiao Wang ${ }^{4 *}$ \\ ${ }^{1}$ Department of Obstetrics and Gynecology, Weifang Maternal and Child Health Hospital, Weifang 261041, ${ }^{2}$ Department of \\ Gynecology, Lin Yi Coal Hot Spring Sanatorium of Shandong Province, Linyi 276032, ${ }^{3}$ Department of Gynecology, Jimo District \\ People's Hospital, Qingdao 266200, " Department of Gynecology, Anqiu People's Hospital, Weifang 262100, Shandong \\ Province, China
}

*For correspondence: Email: zanzianyue7372666@163.com

Sent for review: 6 January 2021

Revised accepted: 22 April 2021

\begin{abstract}
Purpose: To investigate the therapeutic effect of fallopian tube dredging using a combination of hysteroscopy and Traditional Chinese Medicine (TCM) containing marine-derived bioactive principles on patients with inflammatory obstruction of fallopian tube.

Methods: A total of 108 patients with inflammatory obstruction of fallopian tube admitted to Weifang Maternal and Child Health Hospital from February 2017 to February 2018 were enrolled in the study. The patients were randomized into study group $(n=54)$ and reference group $(n=54)$. The reference group received traditional laparotomy, while the study group received fallopian tube dredging using hysteroscopy in combination with TCM containing marine-based bioactive principles. The clinical effects of the two treatments were compared.

Results: The number of completely unobstructed patients was significantly higher in the study group than in the reference group, with lower number of patients unilaterally unobstructed in the study group $(p<0.05)$. No significant differences in the number of bilaterally obstructed patients between the two groups were observed $(p>0.05)$. The study group showed an evidently higher total effectiveness rate than the reference group $(p<0.05)$. Stronger evidence of a higher number of cases of intrauterine pregnancy in the study group than that in the reference group was found, while a strikingly lower number of pregnancy failures and ectopic gestations in the study group was obtained, when compared to the reference group $(p<0.05)$.

Conclusion: Fallopian tube dredging combined with hysteroscopy and TCM containing marine-derived principles effectively improves treatment outcomes in patients with fallopian tube obstruction. Thus, the combination therapy has greater benefits than the traditional approach.
\end{abstract}

Keywords: Fallopian tube, Inflammatory obstruction, Dredging with hysteroscopy, TCM, Marine-derived principles

\begin{abstract}
This is an Open Access article that uses a fund-ing model which does not charge readers or their institutions for access and distributed under the terms of the Creative Commons Attribution License (http://creativecommons.org/licenses/by/4.0) and the Budapest Open Access Initiative (http://www.budapestopenaccessinitiative.org/read), which permit unrestricted use, distribution, and reproduction in any medium, provided the original work is properly credited.
\end{abstract}

Tropical Journal of Pharmaceutical Research is indexed by Science Citation Index (SciSearch), Scopus, International Pharmaceutical Abstract, Chemical Abstracts, Embase, Index Copernicus, EBSCO, African Index Medicus, JournalSeek, Journal Citation Reports/Science Edition, Directory of Open Access Journals (DOAJ), African Journal Online, Bioline International, Open-J-Gate and Pharmacy Abstracts 


\section{INTRODUCTION}

The prevailing rapid pace of modern life has resulted in increased prevalence of infertility $[1,2]$. Research data demonstrate that $10-16 \%$ of young couples suffer from infertility. In terms of causes, infertility is divided into male infertility and female infertility, the latter of which is commonly caused by abnormal fallopian tube, ovulation failure and endometriosis [3-5]. In clinical practice, fallopian tube dredging with hysteroscopy is the primary treatment for inflammatory obstruction of fallopian tube, which has been appreciated by its rapid dredging of obstructed tubes, maintenance of unobstructed tubes, and safety and thoroughness of the operation.

Traditional Chinese Medicine (TCM) containing formulas derived from marine microorganisms belongs to the category of natural drugs that can reduce the adverse effects of drugs on patients [6-7]. The present study was carried out to investigate the therapeutic effect of fallopian tube dredging with combination of hysteroscopy and TCM containing marine microorganism-derived bioactive principles on patients with inflammatory obstruction of fallopian tube. Consequently, clinical data of 108 patients with inflammatory obstruction of fallopian tube admitted to our hospital from February 2017 to February 2018 were retrospectively analyzed.

\section{METHODS}

\section{General information on patients}

We enrolled 108 patients with inflammatory obstruction of fallopian tube who admitted to Weifang Maternal and Child Health Hospital from February 2017 to February 2018. All patients were randomized into study group $(n=54)$ and reference group $(n=54)$. Patients in the study group (mean age $=29.13 \pm 0.94$ years; mean duration of infertility $=2.44 \pm 1.03$ years) comprised 17 cases of primary infertility and 37 cases of secondary infertility. The mean age and mean duration of infertility in the reference group were $29.17 \pm 0.91$ and $2.47 \pm 1.01$ years, respectively. There were 15 cases of primary infertility and 39 cases of secondary infertility in the reference group of patients. The two groups witnessed no statistical differences regarding the clinical data $(p>0.05)$.

\section{Inclusion criteria}

Patients who met the diagnostic criteria for inflammatory obstruction of fallopian tube, and patients with regular menstrual cycle were included in the study. The study was approved by the Ethics Committee of Weifang Maternal and Child Health Hospital, China (approval no. 2017-225). Patients and their families were informed about the purpose of this study and they process involved, and they signed informed consent prior to the commencement of the study [8].

\section{Exclusion criteria}

Patients with other diseases of the reproductive system, patients with surgical contraindications, and those who had cognitive disorders such as mental disorders, as well as patients who refused to participate in, or cooperate, during the study.

\section{Treatments}

Patients in the reference group received traditional laparotomy which was performed 4-6 days after their menstrual period. The patients received general anesthesia while in lithotomy position, prior to salpingostomy. Patients in the treatment group were treated with fallopian tube dredging using a combination of hysteroscopy and TCM containing marine-derived principles. The pelvic cavity, ovaries and fallopian tubes of the patients were observed using hysteroscopy. During the operation, the adhesions around the fallopian tubes were separated.

After the separation, the fallopian tubes were intubated under hysteroscopy, and the patients were injected with $0.5 \%$ metronidazole so as to observe the degree of obstruction of the fallopian tubes. After the operation, the patients were subjected to hydrotubation once a month for 3 consecutive months. In addition, the patients in the study group were given Baogong Zhixue granules (China's National Medical Products Administration approval number no. Z20103059; Manufacturer: Tianjin Zhongsheng Haitian Pharmaceutical Co. Ltd; Specification: $15 \mathrm{~g} \times 8$ sachets) orally, one sachet per administration, twice/day for a treatment course of 14 days, with 2 courses of continuous medication. Ruhesanjie tablets (National Medical Products Administration approval no. Z44020007 Manufacturer: Guangzhou Baiyunshan Zhongyi Pharmaceutical Co. Ltd; Specification: $0.36 \mathrm{~g}$ x $72 \mathrm{~s}$ ) were taken orally, 4 tablets at a time, 3 times/day, with continuous medication for 1 month. Patients in both groups were followed up for 1 year after discharge.

\section{Determination of treatment outcomes}

The degree of obstruction of fallopian tubes after treatment in the two groups were examined. 
Complete absence of tubal obstruction was confirmed when no resistance or slight resistance occurred, with no reflux, during the injection of liquid medicine. Unilateral nonobstruction or bilateral non-obstruction was confirmed with absence of obstruction on one side or on two sides, respectively.

The therapeutic effects were classified as excellent, effective or ineffective, depending on time taken for post-treatment pregnancy to occur. If the patient became pregnant within 6 months after treatment, the treatment outcome was classified as excellent $(A)$, while pregnancies after 12 months was classified as effective (B). On the other hand, the treatment was deemed ineffective $(C)$ if no pregnancy occurred after one year. The total effectiveness $(T)$ was calculated as shown in Eq 1. $T=(A+B) /(A+B+C) * 100 \%$. In addition, pregnancy cases within 1 year of treatment in the two groups were recorded and compared.

\section{Statistical analysis}

Measurement data were expressed as mean \pm standard deviation (SD), and were statistically analyzed with $t$-test. Enumeration data were expressed as number and \%, and were statistically analyzed using $X^{2}$ test. The SPSS21.0 software was used for statistical analysis of data. GraphPad Prism 6 (GraphPad Software, San Diego, USA) was used for drawing data bar charts. Differences were considered statistically significant at $p<0.05$.

\section{RESULTS}

\section{Fallopian tube obstruction}

The study group obtained an apparently higher number of patients who were completely unobstructed in the study group and noticeably fewer patients were unilaterally obstructed, as compared to the study group than in the reference group $(p<0.05)$. However, the two groups did not differ in terms of the number of patients who were bilaterally obstructed $(p>$ 0.05), as shown in Table 1.

\section{Therapeutic effects}

Table 2 clearly presented a better total effectiveness in the study group than the reference group $(p<0.05)$.

\section{Pregnancies within 1-year post-treatment}

The number of intrauterine pregnancy cases in the study group exceeded that in the reference group strikingly $(p<0.05)$. Moreover, strong evidence of a notably lower number of pregnancy failures and ectopic gestation cases in the study group than in the reference group was observed $(p<0.05)$, as shown in Table 3.

Table 1: Fallopian tube obstruction for the two groups post-treatment $\{\mathrm{N}(\%)\}$

\begin{tabular}{lcccc}
\hline Group & $\mathbf{N}$ & Completely unobstructed & Unilaterally obstructed & Bilaterally obstructed \\
\hline Study & 54 & $48(88.89 \%)$ & $6(11.11 \%)$ & 0 \\
Reference & 54 & $38(70.37 \%)$ & $14(25.93 \%)$ & $2(3.70 \%)$ \\
$X^{2}$ & & 5.708 & 3.927 & \\
$P$-value & & 0.017 & 0.048 & \\
\hline
\end{tabular}

Table 2: Treatment effect of the two groups $\{\mathrm{N}(\%)\}$

\begin{tabular}{lccccc}
\hline Group & $\mathbf{N}$ & Excellent & Effective & Ineffective & Total effectiveness \\
\hline Study & 54 & $41(75.93 \%)$ & $12(22.22 \%)$ & $1(1.85 \%)$ & $98.15 \%(53 / 54)$ \\
Reference & 54 & $33(61.11 \%)$ & $12(22.22 \%)$ & $9(16.67 \%)$ & $83.33 \%(45 / 54)$ \\
$X^{2}$ & & & & & 7.053 \\
$P$-value & & & & & 0.008 \\
\hline
\end{tabular}

Table 3: Pregnancy cases within 1-year post-treatment $\{\mathrm{N}(\%)\}$

\begin{tabular}{lcccc}
\hline Group & $\mathbf{N}$ & $\begin{array}{c}\text { Intrauterine } \\
\text { pregnancy }\end{array}$ & Ectopic gestation & Pregnancy failure \\
\hline Study & 54 & $47(87.04 \%)$ & $3(5.56 \%)$ & $4(7.41 \%)$ \\
Reference & 54 & $32(59.26 \%)$ & $10(18.52 \%)$ & $12(22.22 \%)$ \\
$X^{2}$ & & 10.607 & 4.285 & 4.696 \\
$P$-value & & 0.001 & 0.038 & 0.030 \\
\hline
\end{tabular}




\section{DISCUSSION}

Inflammatory obstruction of fallopian tube is one of the main causes of female infertility, with manifestations of increased leucorrhea, abdominal discomfort, dysmenorrhea, and in severe cases, inflammation. Due to the complex mechanism involved in the etiology of this disease, it is imperative to explore effective treatment strategies to improve tubal dredging and restore normal uterine and pelvic functions [9-13]. Female tubal obstruction is a leading cause of infertility mostly because of pelvic inflammation which brings about difficulties with a long treatment cycle and a high possibility of recurrence [14-16]. The combination of fallopian tube dredging and hysteroscopy is widely applied in obstetrics and gynecology for improvement of fertility and quality of life of patients. Hysteroscopy is used to conduct a comprehensive examination of the structure of the uterus and pelvis of patients. Besides, the degree of obstruction of the fallopian tube is observed more clearly by injecting metronidazole solution [17-19].

This study showed that 48 patients $(88.89 \%)$ in the research group were completely unobstructed after treatment, which was significantly higher than 38 patients $(70.37 \%)$ in the reference group. Stuart et al [20] reported that fallopian tube dredging combined with hysteroscopy not only comprehensively and accurately aided the assessment of the structures of fallopian tube and surrounding tissues, but also directly enhanced the assessment of the adhesion and obstruction of patients' fallopian tubes under hysteroscopy, leading to an improved dredging of the fallopian tubes. A study presented a higher number of patients of $32(87.75 \%)$ who were completely unobstructed after operation than the corresponding number of $17(66.38 \%)$ in the control group, indicating that fallopian tube dredging combined with hysteroscopy effectively mitigated tubal obstruction in patients with female infertility, thereby enhancing the probability of pregnancy. Baogong zhixue granules and Mammary nucleus sanjie tablets contain large amounts of marine microorganism-derived agents which exert the effects of removing phlegm, clearing away heat and eliminating dampness, thereby effectively providing antiinflammatory and antibiosis effects.

\section{Limitations of the study}

This single-center study is first limited by the small sample size of only 108 patients in total and 54 patients in each group. Moreover, the one-year follow-up duration of this study is relatively short due to the comparatively longer pregnancy cycle of patients with inflammatory fallopian tube obstruction after treatment.

\section{CONCLUSION}

Fallopian tube dredging using a combination of hysteroscopy and traditional Chinese medicine containing marine-derived bioactive principles effectively improves clinical therapeutic outcomes in patients with inflammatory obstruction of fallopian tube, resulting in enhancement of conception/pregnancy, and the attendant benefits.

\section{DECLARATIONS}

\section{Conflict of interest}

No conflict of interest is associated with this work.

\section{Contribution of authors}

We declare that this work was done by the authors named in this article and all liabilities pertaining to claims relating to the content of this article will be borne by the authors.

\section{Open Access}

This is an Open Access article that uses a funding model which does not charge readers or their institutions for access and distributed under the terms of the Creative Commons Attribution License (http://creativecommons.org/licenses/by/ 4.0) and the Budapest Open Access Initiative (http://www.budapestopenaccessinitiative.org/rea d), which permit unrestricted use, distribution, and reproduction in any medium, provided the original work is properly credited.

\section{REFERENCES}

1. Fraczek M, Piasecka M, Gaczarzewicz D, Szumala-Kakol A, Kazienko A, Lenart S, Laszczynska M, Kurpisz M. Membrane stability and mitochondrial activity of humanejaculated spermatozoa during in vitro experimental infection with Escherichia coli, Staphylococcus haemolyticus and Bacteroides ureolyticus. Andrologia 2012; 44: 315-329.

2. Woodard TL, Hoffman AS, Crocker LC, Holman DA, Hoffman DB, Ma J, Bassett RL Jr, Leal VB, Volk RJ. Pathways: patient-centred decision counselling for women at risk of cancer-related infertility: a protocol for a comparative effectiveness cluster randomised trial. BMJ Open 2018; 8: e019994.

Trop J Pharm Res, May 2021; 20(5): 1082 
3. Socha JK, Saito N, Wolak D, Sechman A, Hrabia A. Expression of aquaporin 4 in the chicken oviduct following tamoxifen treatment. Reprod Domest Anim 2018; 53: 1339-1346.

4. Fernandes CCL, Rodriguez-Villamil $P$, Vasconcelos FR, Nagano CS, Rossetto $R$, Moura AAAN, Rondina $D$. Proteome of the periovulatory oviduct and uterus of goats as related to nutritional balance. Reprod Domest Anim 2018; 53: 1085-1095.

5. Mereness AL, Murphy ZC, Forrestel AC, Butler S, Ko C, Richards JS, Sellix MT. Conditional Deletion of Bmal1 in Ovarian Theca Cells Disrupts Ovulation in Female Mice. Endocrinology 2016; 157: 913-927.

6. Yang XJ, Yang J, Liu Z, Yang G, Shen ZJ. Telocytes damage in endometriosis-affected rat oviduct and potential impact on fertility. J Cell Mol Med 2015; 19: 452-62.

7. Johnston CE, Hartley $C$, Salisbury AM, Wigley $P$. Immunological changes at point-of-lay increase susceptibility to Salmonella enterica Serovar enteritidis infection in vaccinated chickens. PLoS One 2012; 7: e48195.

8. World Medical Association. World Medical Association Declaration of Helsinki: ethical principles for medical research involving human subjects. JAMA. 2013; 310: 2191-2194.

9. Cetin MT, Arisoy AH, Tap O, Kaya M, Urünsak I. Effects of methotrexate on the tubal morphology of rabbits: evaluation by electron microscopy. Gynecol Obstet Invest 2008; 65: 217-221.

10. Sahin C, Mamillapalli R, Taylor HS. Bone MarrowDerived Cells Trafficking to the Oviduct: Effect of Ischemia-Reperfusion Injury. Reprod Sci 2018; 25: 1037-1044.

11. Socha JK, Saito N, Wolak D, Sechman A, Hrabia A. Expression of aquaporin 4 in the chicken oviduct following tamoxifen treatment. Reprod Domest Anim 2018; 53: 1339-1346.
12. Johal T, Kuruba N, Sule M, Mukhopadhyay S, Raje G. Laparoscopic salpingectomy and removal of Essure hysteroscopic sterilisation device: a case series. Eur J Contracept Reprod Health Care 2018; 23: 227-230.

13. Johal T, Kuruba N, Sule M, Mukhopadhyay S, Raje G. Laparoscopic salpingectomy and removal of Essure hysteroscopic sterilisation device: a case series. Eur J Contracept Reprod Health Care 2018; 23: 227-230.

14. Tissot M, Petry S, Lecointre L, Faller E, Baldauf JJ, Akladios C, Boisrame T. Two Surgical Techniques for Essure Device Ablation: The Hysteroscopic Way and the Laparoscopic Way by Salpingectomy with Tubal Interstitial Resection. J Minim Invasive Gynecol 2019; 26: 603.

15. Stuart GS, Ramesh SS. Interval Female Sterilization. Obstet Gynecol. 2018; 131: 117-124.

16. Antoun L, Smith P, Gupta JK, Clark TJ. The feasibility, safety, and effectiveness of hysteroscopic sterilization compared with laparoscopic sterilization. Am J Obstet Gynecol 2017; 217: 570.e1-570.e6.

17. Clark NV, Endicott SP, Jorgensen EM, Hur HC, Lockrow EG, Kern ME, Jones-Cox CE, Dunlow SG, Einarsson Jl, Cohen SL. Review of Sterilization Techniques and Clinical Updates. J Minim Invasive Gynecol 2018; 25 : 1157-1164.

18. Hu C, Chen Z, Chen Y, Hou H, Chen X, Cao Z, Shi H. Analysis of outcomes of fertility restoration surgery in women with infertility secondary to tubal pregnancy: a series of 77 cases. Clin Exp Obstet Gynecol 2017; 44: 195-199.

19. Abdelazim IA, Nussair B, Zhurabekova G, Svetlana S, Abu-Faza M, Naser W. Comment on An Intrauterine Gestational Sac Surrounded by Thin Myometrium at Fundus. J Med Ultrasound 2018; 26: 168-169.

20. Moss C, Isley MM. Sterilization: A Review and Update. Obstet Gynecol Clin North Am 2015; 42: 713-724. 